\title{
Chapter 19 \\ Nature-Based Solutions for Societal Goals \\ Under Climate Change in Urban Areas - Synthesis and Ways Forward
}

\author{
Nadja Kabisch, Jutta Stadler, Horst Korn, and Aletta Bonn
}

\begin{abstract}
Climate change and urbanisation are amongst the greatest global challenges society is facing today. The concept of nature-based solutions has recently been highlighted as key concept in policy and management in achieving alignment of environmental and societal goals (Cohen-Shacham et al. 2016; Kabisch et al. 2016a). The chapters of this volume assess the evidence, debate different concepts, identify policy avenues and display practical management applications that highlight the potential of nature-based solutions in tackling global challenges related to climate change and urbanisation. The authors critically review and present recent findings how urban ecosystem management can be employed to adapt to climate change effects, while at the same time contributing to social and health benefits. The examples discussed for ecosystem services and co-benefits in this volume comprise case studies concerning climate change adaptation by enhancing the regulation of
\end{abstract}

\footnotetext{
N. Kabisch $(\square)$

Department of Ecosystem Services, Helmholtz Centre for Environmental Research - UFZ,

Permoserstraße 15, 04318 Leipzig, Germany

Department of Geography, Humboldt-Universität zu Berlin,

Unter den Linden 6, 10099 Berlin, Germany

German Centre for Integrative Biodiversity Research (iDiv) Halle-Jena-Leipzig,

Deutscher Platz 5e, 04103 Leipzig, Germany

e-mail: nadja.kabisch@ufz.de; nadja.kabisch@geo.hu-berlin.de

J. Stadler • H. Korn

Federal Agency of Nature Conservation (BfN), Isle of Vilm, Germany

e-mail: jutta.stadler@bfn.de; horst.korn@bfn.de
}
A. Bonn
Department of Ecosystem Services, Helmholtz Centre for Environmental Research - UFZ,
Permoserstraße 15, 04318 Leipzig, Germany
Institute of Ecology, Friedrich Schiller University Jena,
Dornburger Str. 159, 07743 Jena, Germany

German Centre for Integrative Biodiversity Research (iDiv) Halle-Jena-Leipzig,

Deutscher Platz 5e, 04103 Leipzig, Germany

e-mail: aletta.bonn@ufz.de 
air quality and temperature, contributing to water cycle regulation, provision of recreation potential as well as improvements for human well-being and mental health. In this conclusion chapter, we summarise the main outcomes of the chapters in this book. Considering current European policy, we develop recommendations for putting nature-based solutions into practice and policy and outline outstanding challenges for science and society.

Keywords Conclusions - Synthesis - Nature-based solutions for climate change adaptation $\bullet$ Planning recommendations $\bullet$ Management applications

\subsection{Introduction}

Climate change and urbanisation are amongst the greatest global challenges society is facing today. The concept of nature-based solutions (NBS) has recently been highlighted as key concept in policy and management in achieving alignment of environmental and societal goals (Cohen-Shacham et al. 2016; Kabisch et al. 2016a). The chapters of this volume assess the evidence, debate different concepts, identify policy avenues and display practical management applications that highlight the potential of NBS in tackling global challenges related to climate change and urbanisation. The authors critically review and present recent findings how urban ecosystem management can be employed to adapt to climate change effects, while at the same time contributing to social and health benefits. The examples discussed for ecosystem services and co-benefits in this volume comprise case studies concerning climate change mitigation via reduction in energy consumption and $\mathrm{CO}_{2}$ emissions, as well as climate change adaptation by enhancing the regulation of air quality and temperature, contributing to water cycle regulation, provision of recreation potential as well as improvements for human well-being and mental health. In this conclusion chapter, we summarise the main outcomes of the chapters in this book. Considering current European policy as well as recommendations drawn by the ENCA interest group on climate change from the outcomes of the European conference on 'Naturebased solutions to climate change in urban areas and their rural surroundings' (Kabisch et al. 2016b), we develop recommendations for putting NBS into practice and policy and outline outstanding challenges for science and society.

\subsection{Climate Change and the Concept of Nature-Based Solutions for Long-Term Sustainability Transition}

Challenges from climate change for urban areas include increasing temperatures and changed precipitation dynamics. Tobias Emilsson and Åsa Ode Sang outline the general impacts and likely direct consequences of climate change for urban areas in Europe, highlighting how NBS through blue and green infrastructure can help to 
mitigate the effects and to adapt to a changing climate. The authors particularly focus on the cooling potential as well as on hydrological, ecological and social factors of urban green and blue spaces. Based on their review of examples, the authors point out that the current planning practice of urban densification poses threats to urban green spaces and brown fields reducing their capacity to serve as NBS for climate change adaptation. They highlight the approach of dual inner urban development as a solution to combine urban development with the quantitative and qualitative improvement of urban green in order to lead to truly sustainable cities. The authors further suggest that when implementing NBS with a particular focus on heat mitigation, the geographical location should be considered. Heatwaves in northern or central European regions that are usually not regularly affected by heat may have more negative consequences on urban residents in these areas, as they may be less prepared and less adapted. The authors stress that the allocation of NBS projects therefore requires a closer assessment of the specific urban morphology and characteristic of local population to arrive at holistic and targeted solutions. NBS may be most important in those areas where excessive urban heat has largest impact or where local residents have less economic possibilities to adapt. Thus, strategic planning in combination with modelling techniques and collaborative processes with the local population is recommended as a way forward to implement NBS for climate change adaptation while taking into account aspects of environmental justice.

In their chapter, Stephan Pauleit and co-authors analyse the features of NBS and other related approaches. They focus on the comparison of an issue-specific approach, such as ecosystem-based adaptation with an infrastructure-related approach, i.e. urban green infrastructure, and more general the concept of ecosystem services and their respective linkages to the NBS concept. In comparison to the other concepts, the authors consider NBS as an umbrella concept that covers features from other approaches, but with a distinct focus on deployment of actions on the ground. Still, the authors argue that ecosystem-based adaptation and urban green infrastructure should be considered as complementary and mutually reinforcing concepts related to NBS. The concept of NBS may build bridges between research, society and practice to find a common understanding and improved communication of what nature is beneficial for and may be easier to understand than the ecosystem service concept. A final conclusion from the authors is that there is still the need to operationalise the concepts to arrive from systematisation at implementation.

When implementing NBS in urban areas, its long-term functionality needs to be considered as Erik Andersson and co-authors point out. The concept of resilience with regard to NBS implies that NBS - once implemented - should not only be considered to be beneficial for current and immediate pressures from climate change but also be able to withstand potential future changes (introduced as a doubleinsurance value by the authors), both environmental and socio-political changes. Long-term resilience thinking of NBS addressed in urban governance therefore requires the consideration of long-term maintenance and the resources required. This is of particular importance because challenges from climate change will further impact on urban society during the upcoming decades and require long-term adaptation thinking (see also Yaella Depietri and Timon McPhearson). 
To accelerate resilient transition thinking for climate change adaptation and mitigation in planning systems, Niki Frantzeskaki and co-authors present a number of European case studies that show how accelerating mechanisms for urban sustainability transitions through NBS unfold in different city contexts. The authors' crosscase comparison resulted in three main recommendations for implementing NBS for accelerating urban sustainability transitions. First, they particularly conclude that it is essential to give support to transition initiatives and urban change agents to mediate and catalyse processes of sustainable transformation. Change agents are central in promoting activities, acting as mediators, translators and networkers, and are further central to identify synergies between departments and sectors. The second important implication is that a proactive collaboration with minimised compartmentalisation is needed as an important precondition for better coordination and policy integration of NBS as part of pathways towards sustainable transition. Third, the authors plea for a policy mix to support long-term stability of projects to enable transition initiatives to spread and scale up. A long-term perspective of local governments on funding is necessary in order to create stability, decrease uncertainty for activities and enable voluntary action for sustainable transition.

\subsection{Evidence of Benefits of Nature-Based Solutions Through Ecosystem Service Provision}

To support the transition towards using NBS for climate change adaptation and mitigation, evidence of the NBS benefits is needed. This can include complementary approaches that combine the benefits of grey-engineered infrastructure and green and blue infrastructure.

In their synthesis, Francesc Baró and Erik Gómez-Baggethun present recent evidence on the potential contribution of regulating ecosystem services that are provided by urban green infrastructure to offset carbon emissions, to reduce heat stress and to mitigate air pollution at different urban scales. Using the city of Barcelona as a case study, the authors show that the real potential of NBS to mitigate carbon emissions, heat and air pollution is often limited and is dependent on geographic location and scale of implementation. The impact is particularly pronounced at the local scale, e.g. around specific green spaces, but does not necessarily scale up to city or municipality scale level. The contribution of urban vegetation to greenhouse gas emission reduction may be relatively limited, while urban soils composed of organic materials can act as much more relevant carbon sinks. Based on literature reviewed in this chapter as well as studies undertaken by the authors in Barcelona metropolitan region, they suggest the magnitude of these environmental problems may be too high to be mitigated by NBS only. The authors further highlight the need to provide good practice examples of NBS implementation projects that provide ecosystem services. Orientation on good practices may improve their uptake and upscaling. Finally, they recommend to place attention to the selection of species as well as on design and management of NBS implementation, as these could affect the degree of ecosystem services provision (see also Vera Enzi and co-authors). 
With regard to disaster risk reduction, Yaella Depietri and Timon McPhearson also highlight the need for a long-term resilience thinking to tackle impacts from climate change and urbanisation. Reviewing the potentials but also the limitations of green and grey infrastructure for disaster risk reduction in urban areas, they suggest that intermediate 'hybrid' approaches, combining both green and grey approaches, may be the most effective strategy for reducing risk from environmental hazards. This is especially the case when NBS approaches may be insufficient to meet the rising impacts of climate change, in case of space limitation or when resource limitations require cost effectiveness in the context of both climatic and economic uncertainty.

A particular part of green infrastructure in cities - riparian forests and wetlands are highlighted as NBS with particular benefits for dense urban areas. Dagmar Haase introduces the management of these habitats as a NBS with multiple benefits that include risk mitigation and adaptation concerning both climate extremes as well as enhanced flood and drought probabilities, while providing co-benefits such as a buffer against high air temperatures, water availability during heatwaves and recreation potential. The author presents several options that show wetland and riparian forests' functionality as NBS to better face the consequences of climate change in cities and urban regions and stresses that urban riparian forest and wetlands need to not only be conserved but also be restored in case of degradation. In line with the previous authors, Dagmar Haase also promotes a hybrid approach of combining natural remnants of wetlands and floodplain forests with technical solutions. To realise 'mini-wetlands' and 'riparian trenches' in areas disconnected from the river may also create new jobs. Following also suggestions by Yaella Depietri and Timon McPhearson, the complementarity of both NBS and technology may be a clever, pragmatic and at the same time innovative solution to complex socio-ecological problems. In addition, potential disservices from urban riparian forests and wetlands, including vector-borne diseases, e.g. transported via mosquitoes, may need to be considered as well with potential negative effects to human health. Careful consideration including such trade-offs can lead to more informed decision-making.

Complementing the contributions by Yaella Depietri and Timon McPhearson as well as Dagmar Haase, in their chapter McKenna Davis and Sandra Naumann also focus on disaster risk reduction and introduce sustainable urban drainage systems (SUDS) as a NBS to flood risk management. Based on their case study analysis, including cost-benefit calculations in comparison with conventional piped drainage systems, the authors conclude that SUDS have a high potential as sustainable, costeffective approaches, which can complement pure 'grey' infrastructure and can be applied within new developments or used to retrofit existing systems. Nevertheless, uncertainties about long-term maintenance, performance and cost (-effectiveness) are main barriers that limit the implementation of SUDS. Authors highlight that making lessons learned and data gathered from existing projects more widely available will support a larger uptake. Maybe most important to support the uptake of SUDS is the fact that NBS such as SUDS can provide multifunctionality, while purely grey and engineered solutions cannot. 
Using the example of green roofs and facades as NBS to climate change adaptation and mitigation, Vera Enzi and co-authors showcase a number of good practice examples highlighting the multiple benefits provided by them. Green roofs and green walls may contribute to the urban biodiversity network and improve air quality and temperature regulation as well as better management of surface water runoff. The authors provide strong business case arguments and show with concrete values that there is already an active green market in the available technology in Europe. In their conclusion, the authors highlight the vision of a resilient city that adapts to climate change needs to focus first on green and then on grey infrastructure. Nevertheless, the authors showed that hesitation, financial barriers for installation and uncertainty about long-term maintenance (costs) still exist. Knowledge needs to be communicated to planners on the potential of ecologically improved technologies for green roof and living walls, their attractive economic 'return on investment' and the range of associated 'free' benefits to society. In fact, using smart incentives could already speed up NBS implementation when taking into account some quality benchmarks as well as existing informal or even formal implementation guidelines that could be used by policy.

\subsection{Health and Social Benefits of Nature-Based Solutions}

Nature-based solutions not only provide climate change adaptation potential, they also offer multiple benefits, in particular health and social benefits related to urban green space distribution in cities.

To assess the health benefits of urban green spaces, Matthias Braubach and coauthors present an in-depth literature review with specific consideration of disadvantaged groups and health inequalities. They highlight increasing evidence that urban green spaces can have substantial benefits for human health and well-being. The evidence for health benefits appears to be very strong in particular for their potential of relaxation, stress reduction and other psychological effects. However, trade-offs of NBS with societal goals include, e.g. allergies to pollen, infections or potential injuries, e.g. by playing outside. Such detrimental effects can, however, be reduced or prevented by proper urban planning, design and maintenance of urban green areas. The authors therefore conclude that the positive health and social effects of urban green spaces significantly outweigh potential trade-offs. Specific recommendations that help implementing urban green spaces as NBS include the development of harmonised approaches to measuring green space benefits, the production of consistent and comparable data across urban areas and the consistent evaluation and monitoring of health effects of NBS implementation. This knowledge is essential for enabling local governments to assess the effects of planning decisions for interventions on environmental and health outcomes and to identify where future NBS implementation projects are most needed.

As health inequalities are expected to grow with increasing urbanisation and climate change, Nadja Kabisch and Matilda Annerstedt van den Bosch discuss 
health benefits from NBS with a particular focus on social justice aspects. They discuss the role of urban green spaces in tackling challenges from both climate change and urbanisation and at the same time counteracting health inequalities across socio-economic status and age scales. Using the case study of Berlin, the authors show that even in cities with comparatively large percentages of urban green spaces, these can be unequally distributed across the city area. Green and blue spaces are not always available in sufficient quantity and may not be easily accessible to all citizens especially vulnerable population groups such as children, elderly or deprived people. In order to provide positive health outcomes for all population groups, an equal distribution of high quality and safe urban natural spaces, adequate for physical activity and play, should therefore be of utmost importance in urban planning for a healthy environment. The authors conclude that quality criteria and standards for urban green spaces and green space implementation projects need to be developed to ensure that they provide the highest number of benefits for most of the potential user groups.

The book section on health and social effects of NBS is complemented by a critical discussion of potential NBS limitations related to social equity, cohesion and inclusion. Annegret Haase develops five hypotheses in which she argues comprehensively that NBS are not a solution for social problems on their own, but need complementary (social and political) tools and instruments. Under particular conditions, NBS might even trigger spatial segregation, e.g. when green space establishments lead to gentrification and displacement of population groups. The author concludes that when discussing NBS as contribution to climate change adaptation and mitigation, both synergies and trade-offs between environmental and social developments should be considered, and possible avenues to avoid or minimise negative impacts on communities should be identified. With this, the author highlights the need to 'politicise' the discourse on NBS and to take into account different power structures and social inequalities when dealing with 'greening' interventions.

Ines Cabral and co-authors discuss urban allotment and community gardens as deliberate NBS. They use the case studies of Lisbon, Leipzig, Manchester and Poznan to illustrate the range of ecosystem services that can be provided by urban gardens. Historically, the primary goal of allotment gardens was to mitigate poverty amongst factory workers during the industrial revolution by providing space for recreation and later to grow food. Thus, allotment gardens can be seen as one of the first multifunctional NBS. In some cities urban allotment gardens present a significant share of the community area and provide ecosystem services. Depending on management type and intensity, urban gardens can foster urban biodiversity and can also play an important role as ecological stepping stones within the city greenspace network. Their contribution to climate change mitigation may, however, be limited, since due to allotment codes, they mostly lack large amounts of biomass, e.g. through large trees, to store or sequester carbon. However, they may provide important climate adaptation potential by providing unsealed ground for water infiltration and by offering citizens spaces to escape the urban heat island effect and opportunities for recreation and other health benefits. Importantly, communal urban gardens can form innovative platforms to experiment with change and to promote social cohesion, an important factor for preparing for adaptation. 


\subsection{Implications for Urban Planning to Implement Nature- Based Solutions}

The final section of the book deals with municipal governance and socio-economic aspects of NBS implementation projects. Good practice examples of efficient governance approaches to implement NBS are shown, and multiple actor-networks are highlighted.

Challenges of NBS implementation through urban governance are addressed by Christine Wamsler and co-authors. They introduce the concept of adaptation mainstreaming which is understood as the inclusion of climate risk considerations in sector policy and practice. The authors present a holistic framework in which adaptation mainstreaming is suggested to increase sustainability and resilience by not only focussing on preventing or resisting climate hazards but by also fostering a broader systems approach that highlights the importance to learn, to live and to cope with potential environmental risks. The authors argue that at the local level, adaptation mainstreaming requires the active consideration and combination of four approaches to reduce climate risk on the ground. These four key principles of the mitigation hierarchy are to avoid and to reduce exposure, to reduce vulnerability and to prepare an effective response or recovery after impact. Green infrastructure as multipurpose measures (e.g. for cooling and drainage) can help to reduce vulnerability through the inclusion of several elements that reduce dependency on only one system. The authors recommend that whenever possible, NBS should be implemented for both multi-hazard and multipurpose measures, i.e. measures that address both adaptation and other municipal objectives. Especially when addressing vulnerability and preparedness of urban communities, a certain redundancy in measures can be an important element of urban design.

Reflecting on institutional aspects and challenges of the implementation of NBS projects, Chantal van Ham and Helen Klimmek highlight the need for increased and improved collaboration between sectors and stakeholders as well as for a sound evidence base on the economic, social and environmental benefits of NBS to foster increasing uptake of NBS in urban areas. Examining different case studies across the world, the authors impressively show how multiple partnerships by different actors and sectors have led to climate change adaptation measures while simultaneously providing social, economic and environmental benefits. Demonstrating and sharing these good practice examples can serve as a strong foundation for promoting, investing and inspiring future collaboration to implement NBS. Authors highlight the importance of multidisciplinary and inclusive partnerships in fostering the uptake of NBS. These can result in the creation of synergies between different actors by bringing together resources, skills and knowledge. The involvement of citizens during project planning was shown to create trust during the implementation process and helped to take over ownership and stewardship. As already recommended by Niki Frantzeskaki and co-authors, the formation of a common understanding helps to establish and accelerate NBS actions. Developing business 
cases from NBS implementation projects can result in important arguments to future investments in NBS implementations by the private sector support and through public investment. Therefore, good and cost-effective practice examples that provide a solid and transparent evidence base need to be disseminated. This will particularly increase visibility of the value of a city's natural assets and may promote the uptake of NBS implementation projects in urban governance.

In their chapter, Jakub Kronenberg and co-authors provide a detailed analysis of the use, understanding and diffusion of NBS in Poland. Using Poland as a postsocialist and post-transformation case, authors highlight that the acceptance of NBS is relatively low, their visibility limited and subsequently implementation of NBS less spread. They see the main reasons for the low acceptance of NBS in Poland partly in the new socio-economic system that was introduced during the transition period after socialism. This may be explained by the fact that societal expectation of modern development in Poland rather correlates with glass and steel dominated grey infrastructure, than with green and blue developments. Powerful decisionmakers do not necessarily work together with NGOs and research institutes that favour the implementation of NBS. To have significant impact, the authors therefore recommend that change agents who promote innovations, as highlighted by Niki Frantzeskaki and co-authors, should selectively work closer with those persons that seem to have the highest potential to accept and promote sustainability transitions through NBS. The authors also conclude that external pressure, especially from the EU (Kronenberg and Bergier 2012), may be particularly helpful in stimulating implementation and acceleration of sustainability transitions. By employing conditional funding, e.g. when granting EU structural funds, EU institutions may act as push factors to change the general framework for the national, social and institutional structures. This policy instrument could be an effective measure by funding agencies to overcome barriers and obstacles that are often created by powerful stakeholders that benefit from investments in grey infrastructure.

Finally, Nils Droste and co-authors focus on fiscal and constitutional restrictions of NBS implementations and analyse solutions to levy greater investments into multifunctional urban NBS. The authors conclude that NBS approaches can provide ecosystem-mediated services that man-made alternatives cannot supply costeffectively. For leveraging investments in urban NBS, cross-sectoral, crossdepartmental planning procedures are required where different interests need to be balanced. The authors suggest that the clearer the 'return of investment' of a NBS implementation is, the more likely it is that respective decision-makers invest in such 'novel' and innovative alternatives to well-known city plans. They further highlight the potential of public-private partnerships to enable urban decisionmakers to create alliances that favour a climate for investments in NBS. Finally, the authors suggest the integration of an ecological indicator into the fiscal transfer system to create a financial incentive for investments into NBS. 


\subsection{Recommendations and Research Challenges to Reach Societal Goals Through Nature-Based Solutions Implementation}

In conclusion, the chapters in this volume provide a compelling account of the increasing evidence of the multiple benefits provided by NBS in combatting climate change, in particular for adapting to a changing climate coupled with increasing urbanisation. Case studies across Europe demonstrate successful implementation of the NBS concept and provide important pointers for urban planning and management.

In order to further operationalise the NBS approach as effective instrument in sustainable urban development at a larger scale, we identify key remaining research challenges that can help to foster broad application in practice and policy:

- Assess effectiveness of NBS at different scales: The NBS impacts of ecosystem service provisions are highly scale dependent concerning space and time and linked to geographical location in the city as well as other factors such as species selection or management practices. Research should therefore identify at what scale and under which circumstances different NBS are most effective in order to evaluate their potential but also possible limitations. It is important that research is not tailored towards single ecosystem services only but takes into account the multiple benefits possibly generated by a NBS project.

- Consider NBS effects of urban soil management: The impact of urban soil management in urban environments, especially the contribution of unsealed soils and high organic soils both to climate mitigation through avoided carbon losses and to adaptation through increased water infiltration and evaporation capacities, needs further scientific attention.

- Evaluate hybrid approaches of NBS and grey infrastructure combinations: As several chapters point out, the dichotomy of employing either engineered or NBS solutions may not be useful or effective. Research should also focus on the question how NBS can complement technological solutions. This includes research that combines effects of the building sector (grey infrastructure) with ecosystem management strategies (blue and green infrastructure) in an integrative manner.

- Analyse cost-benefits of NBS implementation: In order to evaluate the costeffectiveness of NBS, cost-benefit analyses are needed to assess the whole range of possible multiple NBS benefits in terms of single project evaluations as well as in terms of a comparison between purely 'grey' and 'green and blue' and "hybrid" options. This includes economic analyses of the costs of inaction as well as the possibility of catastrophic failure of purely technical solutions. The full range of social and economic impacts should be comprehensively taken into account by studying the monetary and non-monetary values of NBS projects.

- Identify causalities and mechanisms: In order to assess causalities and mechanisms of NBS effectiveness, research set-ups should include an evaluation of all relevant parameters before and after NBS implementation (pre- and post-assessment). Indicators of efficiency should be selected at the beginning of the project and respective measurements undertaken. In addition, the specific contribution 
of biodiversity effects and mechanistic ecosystem functions towards delivery of ecosystem services through NBS need to be disentangled.

- Identify social and environmental synergies and trade-offs of NBS: Holistic research approaches are needed that consider both potential synergies and tradeoffs between environmental and social developments to assess impacts of, for example, potential gentrification, social displacement or spatial segregation effects. Other potential trade-offs on NBS implementation may concern negative health effects, e.g. through potentially enhanced allergies from transmission of pollen from allergenic plants or increased vector-borne diseases through, e.g. creation of favourable habitats for vectors.

- Explore efficiency factors in NBS governance and implementation: Social network analyses and policy analyses may help to assess how successful governance mechanisms can facilitate the participation of relevant institutions and individual actors to arrive at effective decision-making to implement the NBS action. Research should also include the analysis of failure, e.g. why actors do not take decisions in favour of implementing NBS.

\subsection{Recommendations to Foster Wider Application of Nature-Based Solutions with Partners from Society and Policy}

A number of important conclusions can be drawn from the experiences presented in the case studies. This leads to suggestions for policy and practice that also incorporate the recommendations debated by the ENCA (Network of European Nature Conservation Agencies) interest group on climate change from the outcomes of the European conference on 'Nature-based solutions to climate change in urban areas and their rural surroundings' (Kabisch et al. 2016b). These concern three main areas:

Recommendations to ease future NBS implementation projects:

- Demonstrating and sharing: Although a wealth of information on NBS is already available, there is still a need for further collection of case studies and their dissemination through databases and publications. Furthermore, there is also a high demand for synthesis reports, analysing factors of success as well as obstacles encountered and possible ways to overcome them. These need to be produced in accessible formats to urban planners and resource managers. Effective communication of good multipurpose practice examples of NBS implementation projects to planning institutions in other cities will provide orientation and improve NBS uptake and upscaling. Besides information sharing through databases, personal contacts and study visits prove to be important ways of knowledge exchange.

- Minimise compartmentalisation: Urban planning needs to minimise compartmentalisation to improve coordination and policy integration of NBS. A change in planning structures that facilitates better communication and cooperation or the integration of intersectoral departments is recommended. 
- Foster participatory processes for co-design, co-creation and co-management of NBS implementation (Co-Co-Co): NBS should employ multidisciplinary approaches and inclusive partnerships across sectors and with local communities to create and catalyse synergies between different actors. This brings together resources, skills and knowledge. The involvement of citizens during project planning can create trust during the implementation process and helps citizens to take ownership and stewardship of NBS processes and NBS sites. This is important for further maintenance and sustainable management.

- Promote change agents: It has been recognised that individuals, institutions and specific processes that can act as mediators, translators and networkers between the different departments and sectors are central in promoting, accelerating and upscaling NBS implementation projects. These change agents should be actively supported and encouraged to facilitate and promote change through participatory processes.

Recommendations to improve planning processes to NBS implementations:

- Create long-term stability: A mix of different policy instruments for implementing NBS is recommended, such as regulation, financial incentives for public-private partnerships, investments as well as participatory community measures. This may support long-term stability of projects to enable to spread and scale up. Importantly, a long-term perspective of local governments on funding is necessary in order to create stability, decrease uncertainty for activities and enable voluntary action for sustainability transitions.

- Provide monitoring and evaluation: Detailed monitoring and evaluation of NBS before and beyond the project implementation phase will help to identify benefits and potential trade-offs. This information will help to improve management actions that increase the provision of ecosystem services. This again will increase the value of the site for people.

- Develop manuals, guidelines and quality criteria: Based on existing materials, further tools, manuals, guidelines, etc. for practitioners need to be developed in collaboration with science. Evidence and experience-based guidelines about climate change proofing NBS (e.g. species selection) should be developed to ensure that ecological functions and biodiversity gains are resilient to future changes. In some cases, this might mean to be more flexible when considering the provenance of species to be used in a project (e.g. street trees) and give practical advice for the design and management and other relevant aspects of NBS implementation. In addition, quality criteria for urban green spaces as well as their spatial distribution and accessibility need to be developed to ensure that they provide the highest number of benefits for a multitude of potential user groups, especially vulnerable population groups.

- Consider social trade-offs: When planning and implementing NBS projects, potential trade-offs with social developments need to be taken into account in order to avoid gentrification developments resulting in spatial segregation and displacement. Planning authorities should aim for a sufficient quantity and easy accessibility of green and blue infrastructure elements by local city residents as well as high-quality and safe urban natural spaces, adequate for phys- 
ical activity and mental well-being. Efforts should be highest in those areas where climate change impacts are largest or where local residents have least (economic) possibilities to adapt.

- Consider environmental trade-offs: Planning needs to consider the potential disservices when developing, maintaining and managing NBS. Potential trade-offs and ecosystem disservices should be considered, e.g. species selection should consider potential trade-offs to human health such as avoiding the planting of trees or shrubs that cause allergic reactions.

Recommendations to strengthen the business case for NBS implementation:

- Creating and strengthening the business case: Strengthening the business case for NBS through promotion of lessons learned as well as data on costeffectiveness and multiple benefits will result in important arguments to future investments in NBS implementations. Some manuals and tools to evaluate the wider benefits of certain categories of NBS as well as to allow comparisons between 'grey' and 'green' options already exist, while they need further uptake and refinement for other cases.

- Use incentives and new investments: Smart incentives included in municipal planning combined with smart funding instruments could speed up NBS implementation. The European Union and other funding agencies should put an emphasis to favour NBS when granting conditional funds, e.g. structural funds.

- Decrease uncertainty: Certainty about long-term maintenance costs, performance and overall cost-effectiveness of NBS needs to be developed through practice examples in collaboration between practitioners and researchers. A clear expected return of investment of a NBS implementation helps to convince decision-makers to invest in innovative alternatives for a sustainable city planning.

Over the coming years, it will be important to harness linkages and synergies between science, policy and practice to identify sustainable management of urban development by enhancing the contributions urban ecosystems can provide to society. There are opportunities for scientists, policy advisors and resource managers to engage with the ongoing research and practical urban development programmes of the European Commission and the European Environment Agency on nature-based solution in urban areas (European Commission 2015; European Commission 2016) as well as national developments. In addition, the efforts by the World Health Organization (WHO, Braubach et al., this volume; Romanelli et al. 2015) and the International Union for Conservation of Nature (IUCN, Rizvi et al. 2015; Cohen-Shacham et al. 2016) in fostering NBS for environmental, health and human well-being goals in cities and national programmes should be accompanied by local action. Overall, evidence from research and good practice needs to be made available also to the Intergovernmental Platform on Biodiversity and Ecosystem Services (IPBES) to be included in their assessments to synthesise and to communicate knowledge globally.

With intensifying competition for urban space under a changing climate and coupled ongoing urbanisation processes, it will become increasingly difficult to allocate green or blue spaces for a single purpose only or to rely solely on sectoral 
solutions to address mitigation and adaptation to climate change. To enhance preparedness and resilience of urban socio-ecological systems, synergies in urban land use and planning need to be found to align environmental and social goals through NBS. Overall, we hope this volume provides a baseline for stimulating discussion on how to address this challenge to foster integrative governance and management approaches that promote healthy, liveable and sustainable cities.

\section{References}

Cohen-Shacham E, Walters G, Janzen C, Maginnis S (2016) Nature-based solutions to address societal challenges. IUCN, Gland

European Commission (2015) Towards an EU research and innovation policy agenda for naturebased solutions \& re-naturing cities. Final Report of the Horizon 2020 Expert Group on NatureBased Solutions and Re-Naturing Cities

European Commission (2016) Policy topics: nature-based solutions. https://ec.europa.eu/research/ environment/index.cfm?pg=nbs. Accessed 11 Sept 2016

Kabisch N, Frantzeskaki N, Pauleit S, Naumann S, Davis M, Artmann M, Haase D, Knapp S, Korn H, Stadler J, Zaunberger K, Bonn A (2016a) Nature-based solutions to climate change mitigation and adaptation in urban areas: perspectives on indicators, knowledge gaps, barriers, and opportunities for action. Ecol Soc 21:art39. doi: 10.5751/ES-08373-210239

Kabisch N, Stadler J, Korn H, Duffield S, Bonn A (2016b) Proceedings of the European conference on Nature-based solutions to climate change in urban areas and their rural surroundings. BfNSkripten. German Federal Agency of Conservation, Bonn

Kronenberg J, Bergier T (2012) Sustainable development in a transition economy: business case studies from Poland. J Clean Prod 26:18-27

Rizvi A, Baig S, Verdone M (2015) Ecosystems based adaptation: knowledge gaps in making an economic case for investing in nature based solutions for climate change. Gland, Switzerland: IUCN 48

Romanelli C, Cooper D, Campbell-Lendrum D, Maiero M, Karesh W, Hunter D, Golden C (2015) Connecting global priorities: biodiversity and human health: a state of knowledge review. World Health Organisation and Secretariat of the UN Convention on Biological sity, Geneva

Open Access This chapter is licensed under the terms of the Creative Commons Attribution 4.0 International License (http://creativecommons.org/licenses/by/4.0/), which permits use, sharing, adaptation, distribution and reproduction in any medium or format, as long as you give appropriate credit to the original author(s) and the source, provide a link to the Creative Commons license and indicate if changes were made.

The images or other third party material in this chapter are included in the chapter's Creative Commons license, unless indicated otherwise in a credit line to the material. If material is not included in the chapter's Creative Commons license and your intended use is not permitted by statutory regulation or exceeds the permitted use, you will need to obtain permission directly from the copyright holder. 